\title{
What Is a River? The Chicago River as Hyperobject
}

\author{
Matt Edgeworth (narrative) and Jeff Benjamin (photos)
}

What is a river? Dictionaries define rivers as large natural flows of water, crossing or surrounded by land, flowing into an ocean or lake. The common assumption that rivers are natural entities-part of pristine natural cycles and processes-is deeply engrained. But contemporary rivers, as this book and other studies have shown, are far from being wholly natural. On the contrary, they have typically been subject to extensive sculpting and shaping by human beings. The question therefore arises as to whether rivers should be regarded as artificial instead. But that would be equally misleading, for biological and geomorphological processes are still at work even in the most controlled rivers. To insist on seeing rivers as either natural or artificial would be to reproduce entrenched dualistic frames of thought no longer applicable to understanding the hybrid entities of the Anthropocene.

Let us say instead that rivers are complex entanglements of artificial and natural forces-hybrid forms that are neither natural nor cultural, neither human nor nonhuman, neither social nor material, but confluences or mixtures of all these. They can accurately be characterized as "organic machines" (White 1996) or "cyborg-like environments composed of an interconnected and interdependent web of natural and artificial parts" (Scarpino 1997, 5). It might even be argued that human-influenced changes to rivers globally are so great that they helped bring about a new evolutionary stage of rivers in geological terms (Williams et al. 2014).

The study of rivers on a global scale has been facilitated by development of computers and GIS software such as Google Earth. Many researchers in various disciplines now encounter rivers principally via computer screens. Although there 
are considerable advantages afforded by computer technology, however, a problem is the lack of physical engagement with rivers entailed by studying them remotely. For all that is gained through virtual observation and analysis of riverine evidence on multiple scales, something of the material reality of rivers is lost. The force and vibrancy of river forces need to be experienced directly on an embodied level and scale of experience too, which is why a phenomenological approach is adopted in this chapter. "Phenomenology" here simply refers to the study of phenomena as directly experienced. A canoe on the river, rather than a computer console, mediates river encounters.

Imagine an explorer setting off by canoe to explore the natural wonders of the Amazon River. Such an idea (reenacted occasionally but persistently in exploration-themed television programming and geography magazines) appeals to our conceptions of nature as being all around us, as though culture consists of small islands enclosed on all sides by the ocean of nature. But now turn that around and inside-out. The concept of the Anthropocene entails the growing awareness that human culture and technology infiltrates so-called natural systems to a much greater extent than was ever imagined before. We now know, for example, that neither the rain forest of Amazonia nor the river system that supports it are quite as pristine or natural as once assumed (Raffles 2002; Schmidt et al 2014): humans have been thoroughly embedded in forest and river ecosystems for thousands of years. It is still possible to set off on riverine voyages of discovery by canoe, adopting the same spirit of curiosity and adventure that might be taken up if one imagined the river to be a pristine environment. But the wonders to be encountered are the cyborgs and hybrid entities mentioned earlier. Any canoe trip along a river is necessarily a journey through a complex and multifaceted reality, irreducible to parables about nature.

This chapter recounts such a journey, albeit a short one. It tells the story of an encounter with one particular river of the Anthropocene-the Chicago River. Ostensibly a minor river system within a relatively small watershed, it is described here as part of something much larger and more difficult to grasp: a hyperobject. Hyperobjects, to make use of a concept recently developed by Morton (2013), are understood to be "massively distributed in time and space relative to humans," so huge they can never be apprehended in anything like their totality (1). They are part artifacts in the sense that humans have played a role in bringing them into being. In a useful appraisal of the potential relevance of the concept to archaeology, Hudson (2014) refers to them as "dark artefacts." Global warming might be held up as the classic example of a hyperobject. Inadvertently influenced by the industrial activity of human populations in the past, it could conceivably be intentionally shaped in the future. But that does not mean it is or ever could be entirely under human control. It can act independently and unpredictably. It can develop along trajectories that are unintended and unanticipated, and can phase in and out of human experience in unexpected ways. 


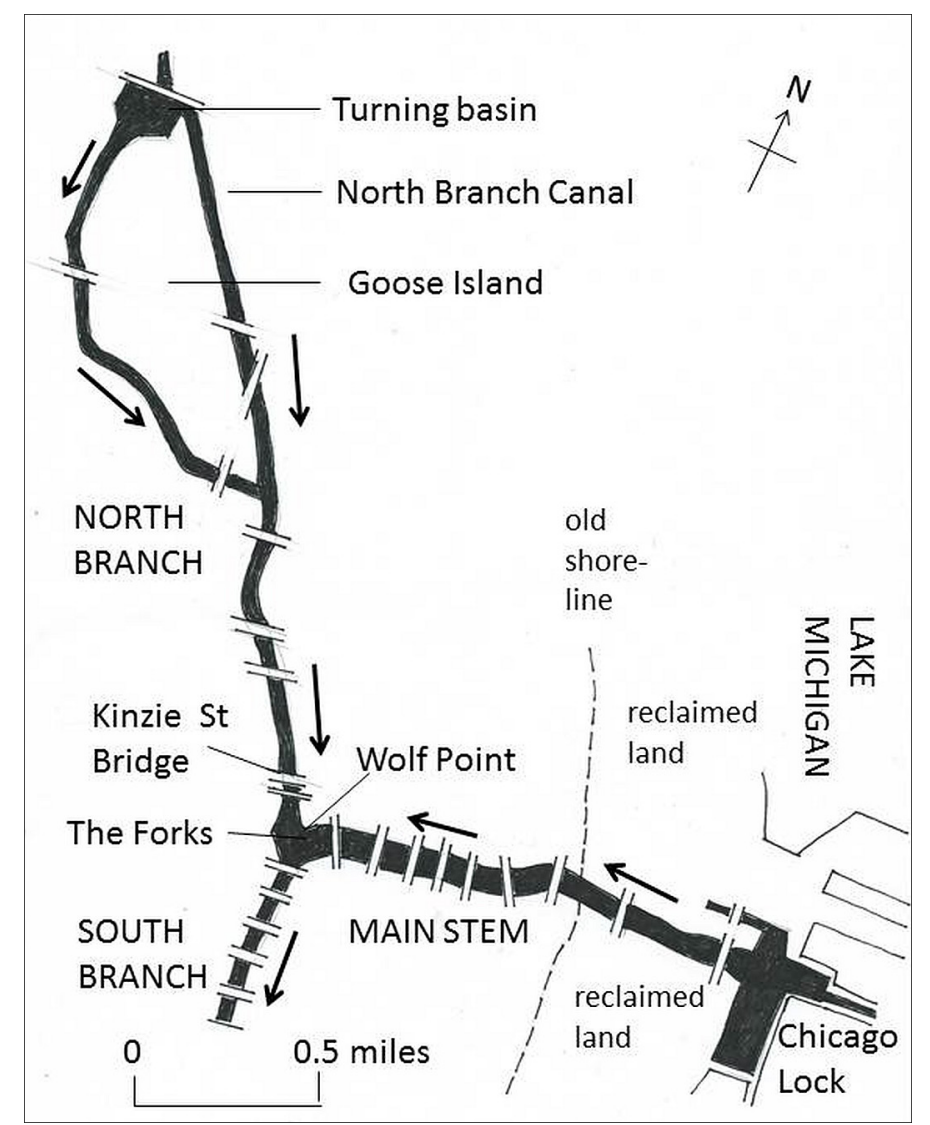

FIGURE 12.1. Map of the North Branch, South Branch, and Main Stem of the Chicago River, showing places mentioned in text. Arrows indicate direction of flow.

\section{BACKGROUND}

It was in a spirit of adventure that two of us set out to explore a short stretch of the Chicago River by canoe. It is common knowledge that the direction of the river's flow was artificially reversed in the 189 os (e.g., Solzman 1998). To anyone interested in archaeology of flow (Edgeworth 2011) this makes the Chicago River worth investigating further. The occasion to do so presented itself in May 2013, while visiting the University of Chicago for a Theoretical Archaeology Group (TAG) conference session titled "Archaeology of the Anthropocene." Archaeologist and artist, Jeff Benjamin, traveled from Michigan with his canoe on top of his car. It is a handmade wooden canoe, not dissimilar to the craft that would have been seen on 
the river before the city of Chicago was built. At 16 feet long, it can accommodate two people comfortably. The day after the conference session, with issues of the Anthropocene still fresh in our minds, we took the canoe to the northern suburbs of the city, where we could gain access to the river.

\section{RIVER EXPLORATION}

We put the canoe on the North Branch of the river at the north end of Goose Island, where there is a turning basin once used for industrial barges. It is the broadest stretch of the Chicago River.

Pushing off from the bank puts you in touch with currents acting on the boat. The flow of the river orients you, and you start to orient yourself in relation to upstream and downstream. Using paddles to propel and steer the canoe places your own human agency-the muscular movements of the body-into an active engagement with river forces. Through the medium of the boat and the paddle you come into contact with the vibrant, flowing materiality of the river.

Heading downstream towards the city, there is a choice as to which way to go. We take the canal route down the east side of the Goose Island. This part of the river is fairly shallow and there are no other boats on this stretch today. The water is smooth. The city lies before us. It is a gentle introduction to the Chicago Area Waterway System.

Goose Island sounds like a "natural" place, but it was formed by the cutting of the North Branch canal in the 1850 os, bypassing a bend in the river for barge traffic. The island thus created became a huge industrial complex known as "Little Hell," lit up all night with blast furnaces and rolling mills (Solzman 1998). River frontage on two sides facilitated movement of goods and materials by barge. It was not just the North Branch canal, but the whole course of the river that was canalizedstraightened, deepened, widened, dredged, and embanked-to allow passage of boats. Today the North Branch canal has partly silted up, "renaturalizing" itself, even if it was not natural to start with. Geese and other waterbirds, flying low and skimming the surface of water, use it as a kind of natural corridor through the city.

Rejoining the main course of the North Branch we go under an increasing number of bridges as we get closer to the city center. Chicago is famous for its movable bridges, with bridge towers for housing lifting or pivoting mechanisms. Of particular interest is the Kinzie Street Bridge. On the south (downstream) side are two fender piles, each consisting of multiple wooden stakes bound together, driven vertically into the riverbed.

It was here in 1992 that an unusual event occurred. An eddy of water and debris several meters across was observed in the river next to these piles, like water going down a very large plughole. At the same time, rising water was noticed in the basements of nearby buildings. It became clear that the river was emptying into a largely forgotten and disused system of freight tunnels, 60 miles in total length, that connected to basements in the city center. A state of emergency was called, and much of the Loop area had to be evacuated (Wilkerson 1992). 


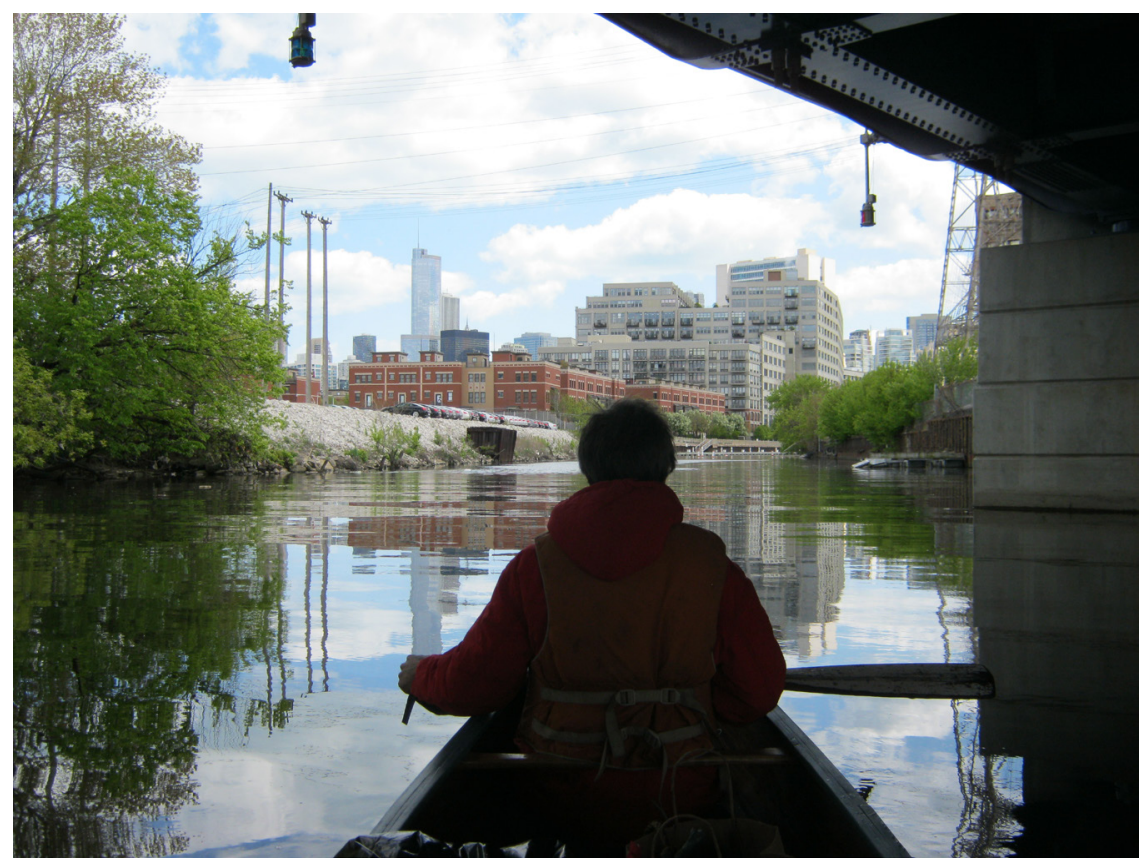

FIGURE 12.2. Heading downstream on the North Branch canal, toward the city center. Photograph by Jeffrey Benjamin.

It later transpired that workers putting in the fender piles the previous year, to strengthen and protect the bridge structure, had inadvertently damaged a section of old freight tunnel 20 feet below the riverbed, pushing displaced clay into the old tunnel wall. A small leak developed, which gradually got worse over the course of several months. Water seeping through the damaged tunnel wall increased until a small hole was created. The flow of water into the tunnel eroded the sides of the hole further until it was several meters across. Hundreds of millions of gallons of water went through the hole into the tunnel system, and from there it started filling up city basements, causing damage that cost over a billion dollars to fix.

It is worth noting that unseen and unsuspected events far below the surface (the flooding of the tunnels) and the existence of subterranean spaces and structures (the disused freight tunnel system) can be indicated by flow patterns on the surface of the river (the eddy of water and debris). The relevance of this will become clear in due course.

Arriving at the confluence of the North Branch, the South Branch, and the Main Stem, we find ourselves in yet another broad turning basin for ships and barges. The confluence has been widened far beyond its original dimensions. A huge iron barge is moored along the western side to our right. 

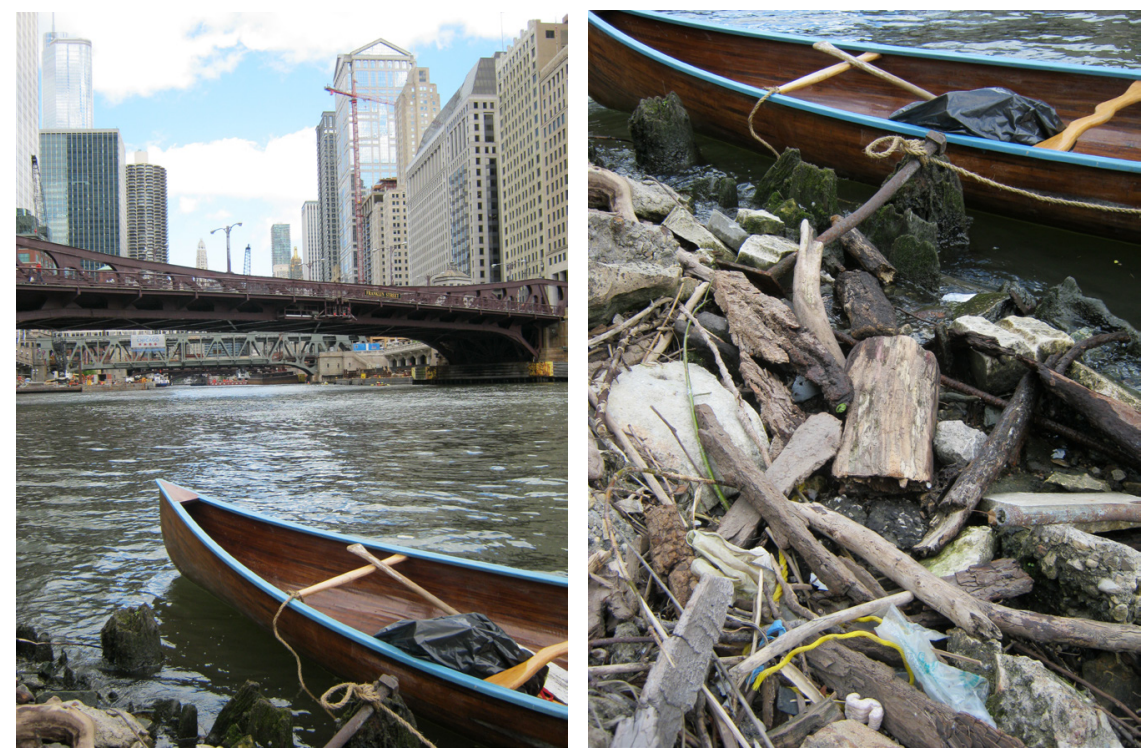

FIGURE 12.3. Wolf Point: (a) view up the Main Stem (b) beached materials. Photographs by Jeffrey Benjamin.

The confluence is at the center of the "Y" that appears so often in civic symbolsthe so-called municipal device-with the stem and two arms of the letter representing the three river branches. Sometimes known as the Forks, this part of the river is in many respects the symbolic heart of the city. Two hundred years ago it was surrounded by creeks and swamps, with a few log cabins. The first bridge over the river was here. Several decades later it was bordered on all sides by lumberyards and stockyards. Now the lumber and cattle have gone. Riverside plots afford prime land for property developments.

We look around for a place to pull into the bank and take in views of the skyscraper city. Finding a good spot is difficult. Along the bank on the left-hand side are underwater forests of thin vertical timber piles with sharp points sticking up just below the surface of the water; we push away from these with our paddles. Eventually we find a way through to the timber frontage of an old wharf-a relic of the time when the riverbank here was the center of the logging industry, and ships stacked with timber from now-vanished forests used to dock here. We moor the canoe, sit on the rocks (some of them are actually lumps of concrete), and eat our lunch. We have arrived at Wolf Point.

Wolf Point is a good place from which to consider the incredible transformations the river has gone through. Originally the Chicago River flowed into Lake Michigan, the source from which city drinking water was taken. But in the late nineteenth century the pollution from sewage and industry and meat 
production got so bad that lake water became dangerous to drink. The radical solution was to reverse the flow of the river-so that it would flow away from the lake. This was achieved partly by the building of the Chicago Ship and Sanitary Canal from the South Branch River into the Des Plaines River to the west. The canal was made progressively deeper the farther from the city it went, drawing the waters of the river into it (Solzman 1998). That meant that Chicago's industrial and sewage effluent flowed into the Illinois and Mississippi Rivers and ultimately all the way to the Gulf of Mexico. It still does. In linking with the larger Mississippi watershed, the Chicago River became part of a greater reality, almost continent-wide.

This has recently given rise to the problem of invasive species threatening to cross over watershed boundaries. The advance upriver of bighead and silver carp is an example. These voracious feeders were originally bred for their great size and rapid growth in Asia, where they were farmed for food over thousands of years. They were introduced into the Deep South to help clean up sewage ponds and commercial fish farm lakes, but some escaped into the river. Now huge shoals are heading up the Mississippi and Illinois Rivers, their numbers multiplying rapidly, threatening to break through electric barriers into the Chicago River and from there into Lake Michigan (Theriot and Tzoumis 2007). It used to be that the pollution in the river was so bad that it formed a toxic barrier through which no living thing could pass. But though still teeming with fecal bacteria, the river is cleaner now, and the formerly impenetrable barrier no longer holds. If the carp get through, they are predicted to transform the fragile ecology of the Great Lakes. There is now talk of reestablishing a more substantial physical barrier, effectively separating river watersheds that were artificially joined over a hundred years ago (Hinterthuer 2012). This would entail, among other things, engineering the rereversal of flow in the Chicago River.

The skyline viewed from Wolf Point is spectacular, but as archaeologists our eyes are also inexorably drawn downward to the ground beneath our feet, as our attention alights on the mundane mixture of materials there.

It is a beach, not of sand and shells, but of artificial and natural materials, some washed up by the river in flood, held in place and stopped from slipping back into the water by the row of half-broken vertical piles. Many different kinds of humanly modified materials are to be seen here among the flotsam and jetsam-plastic bottles and floats, lengths of nylon rope, leather soles, planks and stakes of wood, strips of textile, styrofoam cups. It is a typical assemblage of Anthropocene objects but sorted by the river, thus weighted in favor of things that float and have been carried by the current.

Setting off again from Wolf Point we head up the Main Stem of the river toward Lake Michigan. On either side are soaring cliffs of concrete, metal, and glass, obscured from view only when we pass under the great underbellies of movable bridges. 


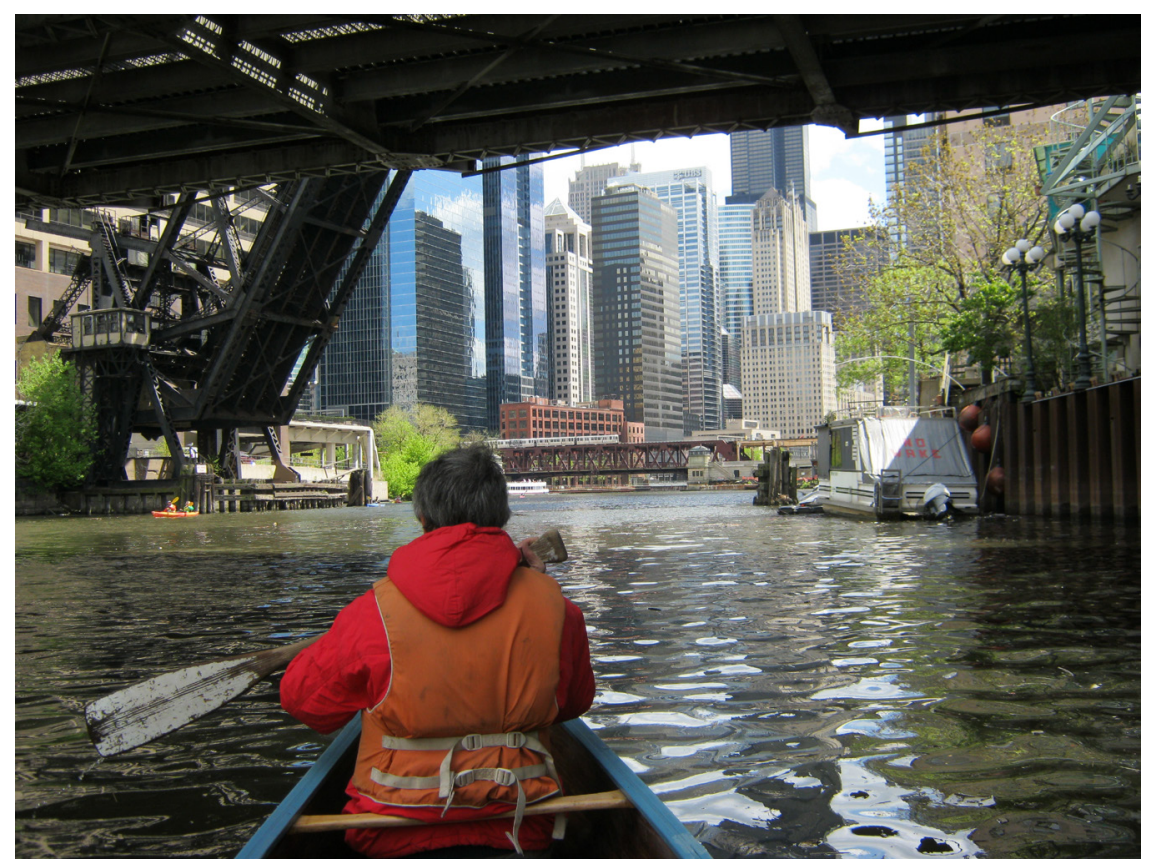

FIGURE 12.4. Skyscraper canyon: heading upstream on the Main Stem. Photograph by Jeffrey Benjamin.

Chicago has always been a river city. City and river are gridded into each other, are parts of the same larger entity. Where is the floodplain of the river? It is integrated into urban architecture and infrastructure. If the river overflows its rusty metal banks, it fills the basements of buildings downtown. Where are the tributaries? The streams that once fed into the river have long since been culverted and incorporated into the system of sewers. Where is the catchment basin? The catchment is a concrete one. When it rains heavily, the impervious vertical and horizontal surfaces of the city-rooftops, windows, streets, curbs, parking lots, gutters-collect and channel storm water directly into the sewage system, instead of absorbing and gradually releasing it as the old wetlands and marshes did.

Now we are heading upstream against the direction of flow (famously reversed) through the skyscraper canyon that is the Main Stem. There are many more vessels on the water here in the city center-speedboats, barges, boats carrying tourists on river architecture tours. The waterway is busy. It is quite hard to find clear water.

Actually, the issue of which way the current is going is not clear cut. At times of heavy flood, river authorities routinely re-reverse the flow of the river to go back into the lake, in order to release pressure on the holding capacity of the river 
system. Taking water out of Lake Michigan instead of putting water into it over the course of a century has lowered the water level in the lake. The lower the lake level goes, the more the river strains to flowing back into it. Left to itself it would reverse back to its primordial direction of flow. Even when the bulk of the river is going the way it is humanly designed to flow, there are other parts going in the opposite direction at the same time. In an important study of flow in the Chicago River, bidirectional flow has been detected (Jackson et al. 2008). Minerals and polluting substances carried in solution find their own depth of suspension, with the heaviest near the bottom. Different layers of the river, being of different densities, react differently to the pull of gravity, thus traveling at different speeds in relation to each other. Thus the river has a kind of stratification. In this case, upper and middle layers go one way, deeper and denser layers go the other. There is overflow and underflow. The river is essentially trying to run in two directions at once.

As tour boats speed by, amplified voices giving historical information come down to us from their elevated decks, wailing in and out of earshot like spoken police car sirens. Muffled echoes of these amplified sounds bounce back from the concrete sides of the river. So do the rolling waves of the water. The best technique is to turn straight into the waves to avoid water swamping the canoe-then get ready for them to bounce back off the banks and hit the canoe from a different direction.

Specific narratives about the history of the river might seem clear and coherent to those on the tour boat deck, whose vantage point moves along with the source of the narration. But down near the surface of the water the arbitrary and foreshortened disembodied facts seem disconnected from the reality of the river itself. They get mixed together in incongruous ways. The water is choppy. So too is the acoustic and linguistic flowscape.

Because there is so much boat traffic we decide not to go all the way up to the river control structures (consisting essentially of a dam and lock) where the Main Stem meets Lake Michigan. Instead, we head back the way we came, past Wolf Point and up the North Branch.

It is worth noting that the Main Stem of the Chicago River is much longer today than it was 150 years ago. Not only is the stretch of river from Michigan Avenue to Lake Michigan entirely human-made, but so too is the ground on either side. It is all landfill. Rubble and charred debris from the Great Fire of Chicago in 1871 was dumped along the lake shoreline, and added to subsequently by spoil from excavation of basements and underground railways. As the reclaimed land pushed outward into the lake, forming what is now Grant Park, so the river lengthened accordingly.

Back on the North Branch, we take the river route around the west side of Goose Island this time. It is good to reach calm water again. There are no other boats on the river here. 

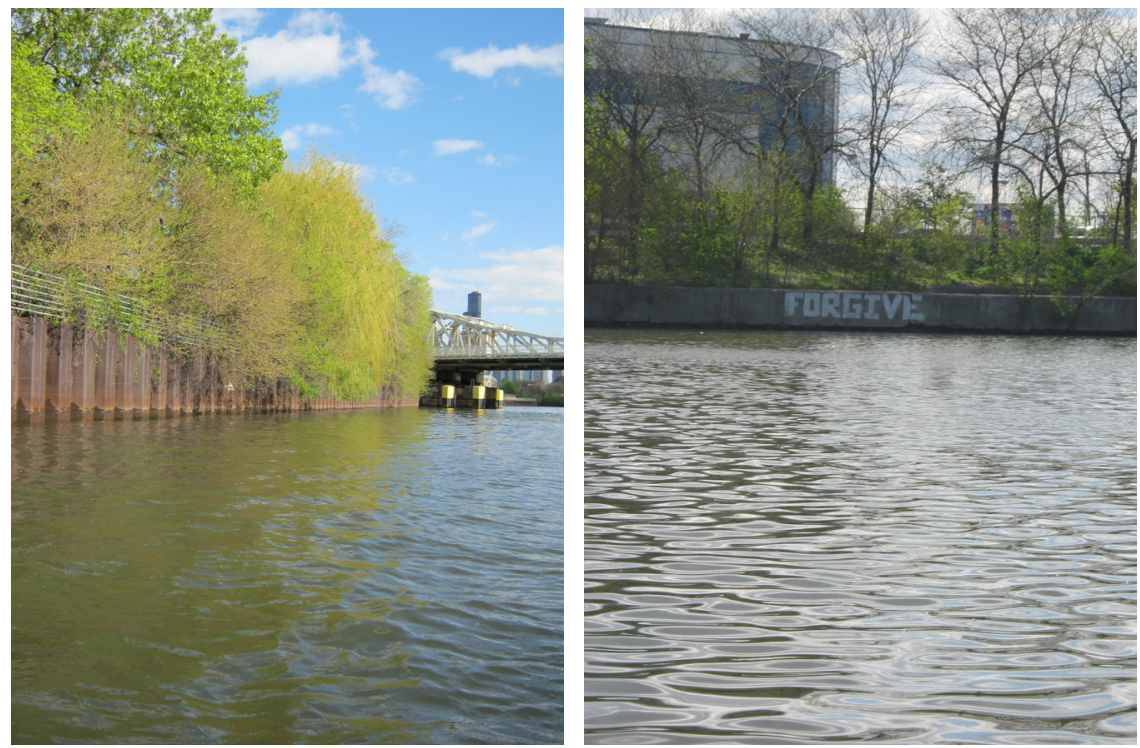

FIGURE 12.5. The embanked river: (a) metal bank (b) concrete/earthen bank, with graffiti. Photographs by Jeffrey Benjamin.

Land on either side of the North Branch River is heavily industrialized. Goose Island is on the east bank. On the west bank is a salt packaging and warehouse facility. The vertical banks of the river are faced with retaining sheets of smooth or corrugated metal, allowing large barges bringing materials to dock and unload but making it impossible for a canoeist to pull a small boat into the shore and disembark. The old creeks and gullies and gently sloping banks have been replaced by vertical walls - metal in places, concrete elsewhere-which sharply separate the water from the land.

This is where something strange starts to happen-where our encounter with the river really begins. At first the signs are subtle, barely noticed. A slight difficulty in steering the boat. It is as though something is trying to spin the boat around, pushing the stern first this way, then that. It gets worse. Soon the movement of the boat becomes extremely erratic, almost out of control.

There are pros and cons of using small boats to explore rivers. Gone is the detached stance of an objective observer, and instead one assumes the more engaged attitude of an active participant. There is the sense of being in touch with the river and its flow. Being situated in the riverscape, you can act on the river and the river can act on you. Sometimes this develops into something like a wrestling match, with participants locked together in move and countermove. No true river encounter is possible without this interplay of human and river forces. Such an interplay 
necessarily includes within it the possibility that the river might exert its forces in undesired and unexpected ways.

Suddenly we are rising and falling on a series of large waves. There is a swell on the river estimated to be about 4 to 5 feet from peak to trough, with about 20 to 30 feet and 3 to 5 seconds from the peak of one wave to another - the kind of swell one might encounter on the sea or a large lake, whipped up by the wind, perhaps in the wake of a storm. It is difficult to tell which way it is going as it rebounds from one metal side to the other, almost breaking into turbulence where waves from different directions meet. We ride it out. It lasts a couple of minutes, and then the river reverts to its former calm state. What makes the experience so uncanny is that there is nothing at all to explain it. No boats. No wind. No impending storm. No sluices opening or closing on the side of the river. Nothing visible on the surface, upriver or down, that could have caused the river disturbance.

So far in this chapter there has been no mention of Deep Tunnel. It has been there throughout our journey, an unseen presence, about 200 feet below the riverbed. Now it is important to bring it into the discussion. Deep Tunnel is effectively an artificial underground river, concrete-lined, shadowing the course and gradient of the surface watercourse and connected to it by a network of interceptor tunnels, drop shafts, sewers, reservoirs, and pumping stations. Up to 30 feet in diameter, it extends for 110 miles in linked sections beneath the North Branch, Main Stream, South Branch, Calumet, and Des Plaines Rivers. It is one of the engineering marvels of the contemporary age.

The purpose of Deep Tunnel is to take the overflow of combined sewage and storm water from the city sewer and drainage systems that would otherwise empty into the river, to divert it into temporary holding reservoirs, to process it, pump it back to the surface, and return it into the river in a controlled manner (Scalise and Fitzpatrick 2012). The success of Deep Tunnel can be measured in the cleaner water of the Chicago River, though an unintended consequence (of removing the toxic barrier between watersheds) was to open up a possible gateway for invasive species to cross from one watershed to another, as discussed earlier.

The control structures of Deep Tunnel, regulating overflows and diversions of flows into and out of the river, are computerized. Technological systems and river are intermeshed. That makes it sound as though things are entirely under control, which is not always the case. In 1999 a powerful shock wave traveled the wrong way up the Main Stream section of the tunnel, causing immense amounts of damage. The wave surged downstream, rebounded at the end, then surged upstream, meeting itself on the way, strangely echoing the tendency of the surface river to try to go in both directions at once (Kendall 1999).

Combined storm water and sewage can travel the wrong way vertically as well as horizontally. In 1986 a full-to-capacity Deep Tunnel sent water surging up drop shafts like volcanic lava from the bowels of the earth, to erupt as geysers 65 feet high downtown, catapulting manhole covers into the air and flooding streets and basements with raw diluted sewage (Karwath 1986). 

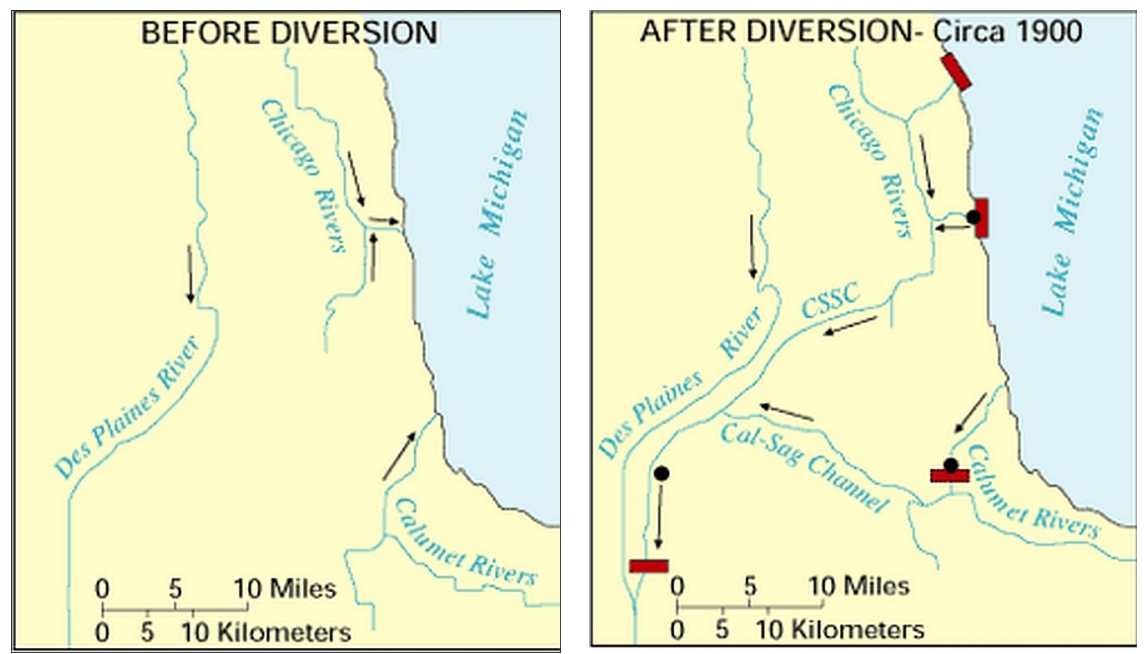

FIGURES 12.6A and 12.6B. Direction of flow of the Chicago River before after its reversal in 1900. Red blocks indicate positions of river control structures. United States Geological Survey.

We arrive back at the turning basin where we had set off, pulling the canoe back up onto the jetty in the knowledge that something significant has just occurred but not sure exactly what it was that we experienced, or how it could be explained.

It is difficult to say for sure, but Deep Tunnel probably had something to do with the river disturbance that we encountered. An inference drawn here is that when near full capacity, pressure within Deep Tunnel sends water backflowing up drop shafts into sewage interceptor tunnels and from there through automatic underwater control gates into the river. We just happened to be passing over such a gate when it opened. Alternatively, it may be that the drop shafts are closed off when Deep Tunnel is full, leaving nowhere for excess storm water in subsurface sewers to go except through outflow tunnels into the river. Both scenarios go some way toward explaining the hundreds of combined sewage outflows (CSOs) that take place each year, many of them on the North Branch, not all of them anticipated or recorded.

\section{CONCLUSION}

What kind of entity is the Chicago River? The dictionary definitions of rivers as natural watercourses flowing into an ocean or lake seem to fall hopelessly wide of the mark. This particular river is clearly much more than a natural flow of water; moreover it flows away from the lake it once flowed into.

One of the difficulties of describing rivers of the Anthropocene is finding the categories in which to place them, and the metaphors with which to describe them. The river in this case cannot be separated from control structures and river 


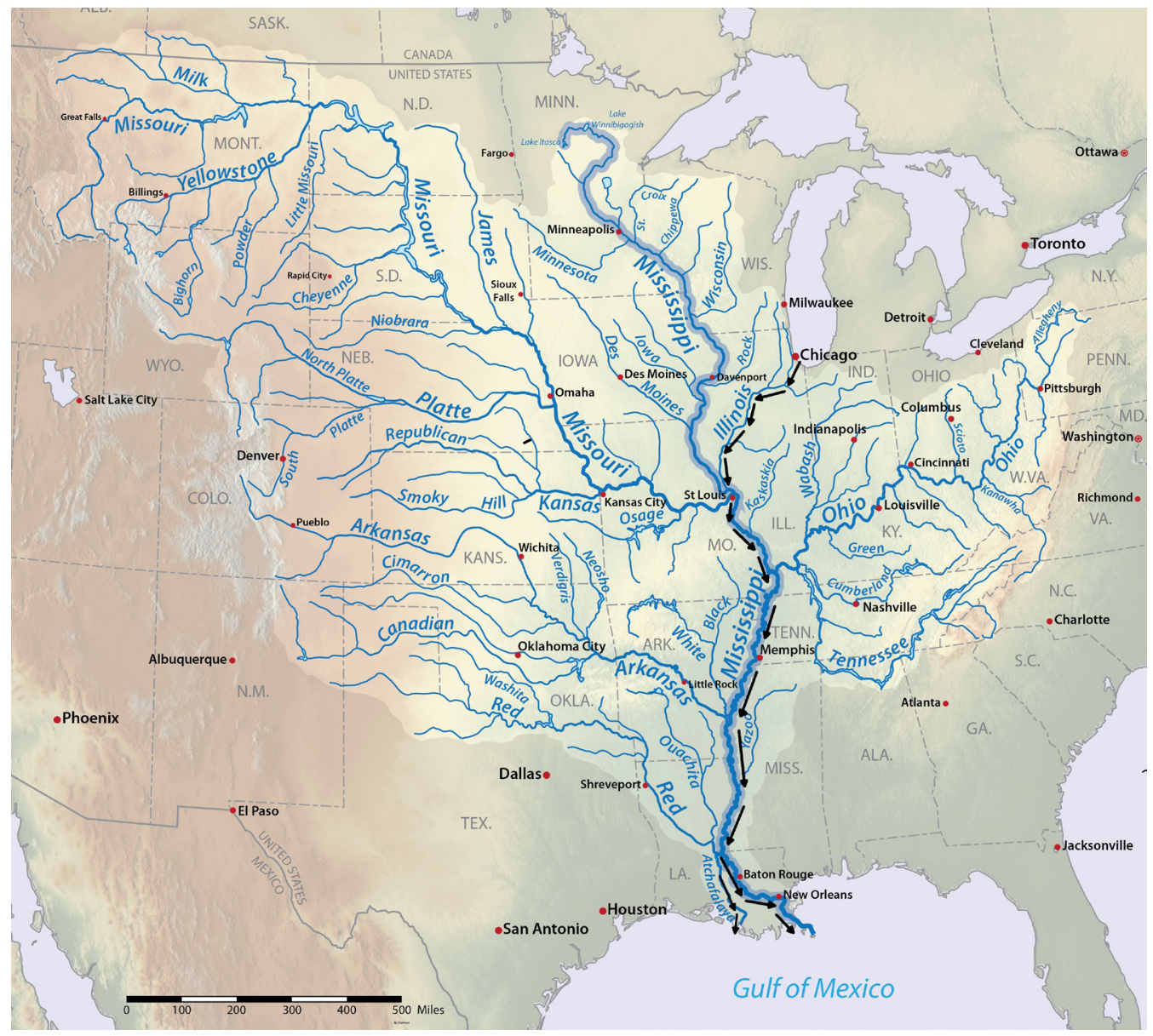

FIGURE 12.7. Flow of water (and sewage) from the Chicago River through other river systems into the Gulf of Mexico. Adapted from map by Shannon 1, CC by 4.o.

barriers, artificial embankments, concrete catchments, sewer and drainage networks, underground reservoirs and pumping stations, engineered flow regimes, and so on. From our encounter with it, there is a sense in which it is a partial manifestation of something much greater, the full extent of which we have not yet fully grasped. This is where Timothy Morton's concept of hyperobjects comes in. It stretches our concepts of time and space, challenging our notions of what objects are, while providing space for conceptualizing things that do not fit within usual frameworks. Hyperobjects are so large and multifaceted and spread out through time that they cannot be apprehended in one go, and they have aspects to them 
that may be hidden and inaccessible, phasing in and out of human awareness (Morton 2014).

The river might be considered part of something like that, which we just skimmed the surface of during our trip. For all that we have tried to formulate a phenomenological approach in this chapter, we are dealing with an entity that extends beyond perceived phenomena and the limits of embodied, situated perceptions in any given spatial and temporal context. It is larger than the river watershed, with arms or branches reaching as far away in space as the Gulf of Mexico. It is as tall as a city and has roots that go farther than one might think into the depths of the earth.

This is more than just a hybrid entity, organic machine, or cyborg. It is a hyperobject. 
